\title{
An Epistemological Misalignment of Cogs in the Al-Art-Making Machine
}

\author{
Anton Dragan Maslic \\ School of Creative Media, City University of Hong Kong \\ Kowloon Tong, Hong Kong \\ tony.maslic@my.cityu.edu.hk
}

\author{
Eugenia S. Kim \\ Leonardo21 \\ Central, Hong Kong \\ leonardo21hk@gmail.com
}

\section{INTRODUCTION}

Artist, designer, engineer, programmer, technologist and creator are all terms used to describe various roles within the new media art community. It would be easy to assume that there is consensus between these collaborators on the understanding and use of technology. Yet the reality may be quite different - especially in the case of artificial intelligence (Al).

Historically, individuals in the creative disciplines have embraced Al since its inception into both practice and research to produce new media art. In recent times, however, artworks typically employ only a subset of Al technologies, namely machine learning (ML) and deep learning (DL). There may also be differing opinions on what to prioritize: developing a new algorithm, a novel process or producing an aesthetically remarkable output.

The authors first encountered these epistemological challenges as studio-trained interdisciplinary artists and practice-based researchers beginning to integrate $\mathrm{Al}$ into their research. Issues discussed here include the challenges of designating universally or unequivocally accepted definitions, the cultural contexts within which technology exists, and how "processed" a technology becomes as a tool can change the language being used.

\section{A BRIEF OVERVIEW OF AI}

The early pioneers of $\mathrm{Al}$ were inspired by mankind's universal fascination with thinking machines, which started with the ancient Greeks fantasizing through mythology about intelligent mechanical men on the threshold between gods and machines (Mayor, 2018). Dreams of intelligent machines were popularized through science fiction literature from the mid-19th century and became a genre that was gradually accepted as a serious literature form. It is difficult to precisely trace back the origins of $\mathrm{Al}$ as the hard facts are usually obscured by a non-cohesive distributed effort across disciplines and geographic locations. Alan Turing's seminal 1950 publication was a major influence with the term 'Al' itself coined at the 1956 Dartmouth Summer Research Project on Artificial Intelligence (DSRPAI) by John McCarthy (EUR 30221 EN, 2020). DSRPAl was the brainchild of John McCartney, Marvin Minsky, Claude Shannon and Nathaniel Rochester - young visionary maverick scientists interested in the threshold between creative arts, literature, mathematics and computer science who came together to form a conference that would take the thinking machines as their core concentration (McCarthy et al. 2006).

This conference, which was chaotic in nature, still prompted $\mathrm{Al}$ as a serious science discipline that could generate large amounts of funding in the following years. The cross-disciplinarity of Minsky further increased the popularity of $A l$ in several different disciplines from art to philosophy. Initially a science fascinated by cognitive machines, Al would change radically in the following years of research and development.

\subsection{Key terminology and concepts}

In practice, Al still does not have a universally recognized definition in its originating field of computer science, leading to their own disputes over terminology (Wang 2019). Simply put, Al can be summarized in three phases starting in the 1950s: Foundation (1950s-1970s, methods and algorithms), Symbolic (1970s-1990s, model-driven, knowledge-based systems), and ML/DL (1990s present, data-driven) (EUR 30221 EN 2020). To that end, we identified a number of common terms and concepts that are associated with $\mathrm{Al}$ (as seen in Table 1). Of these terms, "computational creativity" also appeared as an alternative for describing artistic activity involving $\mathrm{Al}$ (Lopez de Mantaras 2016). 
Table 1: Frequently used terminology by category

\begin{tabular}{|c|c|}
\hline Types of Al & General, Narrow, Strong, Super \\
\hline $\begin{array}{c}\text { Types of } \\
\text { Learning }\end{array}$ & $\begin{array}{c}\text { Supervised, Unsupervised, } \\
\text { Semi-supervised, Reinforced }\end{array}$ \\
\hline \multicolumn{2}{|c|}{ Al -> Machine Learning -> Deep Learning } \\
\hline $\begin{array}{c}\text { Types of } \\
\text { Neural } \\
\text { Networks }\end{array}$ & $\begin{array}{c}\text { Artificial (ANN), Recurrent (RNN), } \\
\text { Convolutional (CNN), Deep, } \\
\text { combinations of multiple models }\end{array}$ \\
\hline $\begin{array}{c}\text { Other Key } \\
\text { Terms }\end{array}$ & $\begin{array}{c}\text { Generative Adversarial Networks } \\
(G A N), \text { Creative Adversarial Networks } \\
(C A N) \text { Natural Language Processing } \\
\text { (NLP), Computational Creativity }\end{array}$ \\
\hline
\end{tabular}

\subsection{Presence in new media art}

The field of computer music was a source of early Al and new media projects, starting with Minsky (Lopez de Mantaras 2016). Amongst visual artists, nature has a significant influence as seen in the work of Harold Cohen and Jon McCormack. The addition of GANs/CANs have enabled artists to collaborate with machines to generate serendipitous new work such as Blackberry Winter (Loclair 2019) and AICAN (Mazzone and Elgammal 2019). More recently, artists have access to free online training tailored to their needs or as part of a formal degree through academic institutions (Goldsmiths University of London 2021; Wolz and Wilson 2020).

One trend to note is the option of using a coding tool such as Rebecca Fiebrink's Wekinator (Goldsmiths University of London, 2021). This approach to training deviates from that offered in business and engineering courses, which tend to focus on the mathematics and high-level programming required to create an original application. Artists such as Loclair do program their own bespoke tools, but the levels of engagement available is perhaps one of the reasons leading to confusion within new media art. In some ways, this period is supportive of this ambiguity as it allows multiple options: work from scratch, use readymade platforms, use tools derived from these platforms or customize a solution as needed. This flexibility allows artists to produce and contribute to the growing body of $\mathrm{Al}$ based artworks regardless of their technical background.

\section{REFLECTIONS AND CONCLUSION}

As we are researchers who are neither purely artists nor technologists, we both found ourselves coming from a hybrid perspective regarding Al. In reviewing the history of $\mathrm{Al}$ and its application to new media art, we confirmed two basic truths: computational creativity is not "new" and that it is not only artists who are confused about terminology. It seems that the intertwined issues of diversity, inclusivity and community also lead to and complicate factionalization amongst artists and technologists alike. Broader factors such economics, politics, and ecology incentivize "cutting edge" projects which may discourage potential collaborations for the sake of personal reputation. Our counterargument is that it is still the "concept" and not the "technology" involved that makes something innovative and reflexive to society at large. Redefining, clarifying and streamlining all terminology regarding Al will both ease and bridge any existent inconsistencies and perturbations between artists and engineers. By demythologizing $\mathrm{Al}$ as a magical superpower, it can then be more properly appreciated as the tool it is. This shift in mindset will enable more effective collaborations and increased production both of knowledge and art objects.

\section{REFERENCES}

EUR 30221 EN (2020) Historical Evolution of Artificial Intelligence. Publications Office of the European Union, Luxembourg.

Goldsmiths University of London (2021) Machine Learning for Musicians and Artists. https://www.kadenze.com/courses/machine-learning-formusicians-and-artists/info (retrieved 16 March 2021).

Loclair, C.M.. (2019). Blackberry Winter. https://christianmioloclair.com/blackberrywinter (retrieved 16 March 2021).

López de Mántaras, R. (2016) Artificial Intelligence and the Arts: Toward Computational Creativity. In The Next Step: Exponential Life. BBVA, Madrid.

Mayor, A. (2018). Gods and Robots-Myths, Machines, and Ancient Dreams of Technology. Princeton University Press.

Mazzone, M. and Elgammal, A. (2019). Art, Creativity, and the Potential of Artificial Intelligence. Arts, 8(26), 1-9.

McCarthy, J., Minsky, M., Rochester, N., and Shannon, C. (1955) A Proposal for the Dartmouth Summer Research Project on Artificial Intelligence. http://www.formal.stanford.edu/jmc/history/dartmouth.htm I (retrieved 16 March 2021).

Wang, P. (2019) On Defining Artificial Intelligence. Journal of Artificial General Intelligence, 10(2), 1-37.

Wolz, U. and Wilson, J. (2020) Coding in the Liberal Arts through Natural Language Processing and Machine Learning. The Tenth AAAI Symposium on Educational Advances in Artificial Intelligence (EAAI-20), New York, New York, 7-12 February 2020, 13506-13507. AAAI Press, Palo Alto, California. 